\title{
Glutaric Acid and Its Metabolites Cause Apoptosis in Immature Oligodendrocytes: A Novel Mechanism of White Matter Degeneration in Glutaryl-CoA Dehydrogenase Deficiency
}

\author{
BETTINA GERSTNER, ALEXANDER GRATOPP, MONIKA MARCINKOWSKI, \\ MARCO SIFRINGER, MICHAEL OBLADEN, AND CHRISTOPH BÜHRER \\ Departments of Neonatology [B.G., A.G., M.M., M.O., C.B.] and Neuropediatrics [M.S.], Charité Campus \\ Virchow-Klinikum, D-13353 Berlin, Germany
}

\begin{abstract}
Glutaryl-CoA dehydrogenase deficiency is an inherited metabolic disease characterized by elevated concentrations of glutaric acid (GA) and its metabolites glutaconic acid (GC) and 3-hydroxy-glutaric acid (3-OH-GA). Its hallmarks are striatal and cortical degeneration, which have been linked to excitotoxic neuronal cell death. However, magnetic resonance imaging studies have also revealed widespread white matter disease. Correspondingly, we decided to investigate the effects of GA, GC, and 3-OH-GA on the rat immature oligodendroglia cell line, OLN93. For comparison, we also exposed the neuroblastoma line SH-SY5Y and the microglia line BV-2 to GA, GC, and 3-OHGA. Cell viability was measured by metabolism of 3-(4,5dimethylthiazol-2-yl)-2,5-diphenyl tetrazolium. Flow cytometry was used to assess apoptosis via annexin- $\mathrm{V}$, anti-active caspase-3 antibody, and propidium iodide staining. GA, GC, and 3-OH-GA reduced OLN-93 oligodendroglia cell viability in a dosedependent manner. Toxicity of GA, GC, and 3-OH-GA was abrogated by preincubation with the pan-caspase inhibitor $\mathrm{z}$ VAD-fmk. Apoptosis but not necrosis was detected at various stages (early: annexin- $\mathrm{V}$; effector: caspase-3) after 24-48 h of incubation with GA, GC, or 3-OH-GA in OLN-93 but not in
\end{abstract}

\section{ABSTRACT}

neuroblastoma or microglia cells. OLN-93 lacked expression of $\mathrm{N}$-methyl-D-aspartate receptors, making classical glutamatergic excitotoxicity an unlikely explanation for the selective toxicity of GA, GC, and 3-OH-GA for OLN-93 cells. GA, GC, and 3-OH-GA directly initiate the apoptotic cascade in oligodendroglia cells. This mechanism may contribute to the white matter damage observed in glutaryl-CoA dehydrogenase deficiency.

(Pediatr Res 57: 771-776, 2005)

GA, glutaric acid

\section{Abbreviations}

GC, glutaconic acid

GDD, glutaryl-CoA dehydrogenase deficiency

GYKI, 4-(8-Methyl-9H-1,3-dioxolo[4,5-h][2,3]benzodiazepin-

5-yl)-benzenamine hydrochloride

MK801, dizocilpine

MRI, magnetic resonance imaging

MTT, 3-(4,5-dimethylthiazol-2-yl)-2,5-diphenyl tetrazolium

NMDA, N-methyl-D -aspartate

3-OH-GA, 3-hydroxy-glutaric acid
Glutaryl-CoA dehydrogenase deficiency (GDD; also called glutaric aciduria type I; McKusick 231670) is an inherited metabolic disease resulting from deficiency of glutaryl-CoA dehydrogenase (EC 1.3.99.7). This disease is characterized by

Received March 4, 2004; accepted October 13, 2004.

Correspondence: Bettina Gerstner, M.D., Klinik für Neonatologie, Charité Campus Virchow-Klinikum, Augustenburger Platz 1, D-13353 Berlin, Germany; e-mail: bettina.gerstner@charite.de.

Supported in part by grants from the German Federal Department of Education and Research (BMBF, 01 ZZ 0101), Bonn, and the Wilhelm Sander Stiftung (2000.091.1), Munich.

Presented in part at the annual meeting of the European Society for Pediatric Research; Bilbao, Spain, September 2003.

DOI: 10.1203/01.PDR.0000157727.21503.8D accumulation of glutaric acid (GA), 3-hydroxy-glutaric acid (3-OH-GA), and glutaconic acid (GC). Whereas the concentrations of GA, 3-OH-GA, and GC may rise to millimolar concentrations in various body fluids during acute crises, signs of tissue damage are restricted to the CNS.

Hallmarks of GDD in magnetic resonance imaging (MRI) studies of the brain are atrophy of the basal ganglia and the frontotemporal cortex (1). Two mechanisms that mediate neurotoxicity of GA and 3-OH-GA have been established in neonatal rat brain tissue homogenates, primary chick embryo neuronal cultures, and neonatal rat brain slice cultures: excitotoxicity mediated by N-methyl-D-aspartate (NMDA) receptors $(2,3)$ and mitochondrial production of reactive oxygen species 
(4-6). However, detailed MRI studies have also revealed delayed myelination (1) and a variable degree of periventricular white matter disease $(7,8)$ in addition to the neuronal atrophy observed. In adult-onset GDD, leukoencephalopathy is the leading MRI finding (9). In a mouse model of GDD, there is no evidence of neuronal loss, whereas there is diffuse spongiform white matter disease (10). No pathophysiologic explanation for oligodendroglial cell destruction has been reported so far. To improve clinical understanding of this topic, we investigated the impact of GA, 3-OH-GA, and GC on the immature oligodendrocyte cell line OLN-93 and assessed mechanisms of cellular damage that are triggered by GA, 3-OH-GA, and GC.

\section{METHODS}

Cells. The permanent oligodendrocyte cell line OLN-93, derived from spontaneously transformed cells in primary rat brain glia cultures (11), was provided by Dr. C. Richter-Landsberg (Oldenburg, Germany). OLN-93 cells bear the morphologic and antigenic properties (A2B5-, galactocerebroside + , myelin basic protein + , Wolfgram protein + , proteolipidprotein + ) of 5 - to 10 -d-old (postnatal time) cultured rat brain oligodendrocytes. These resemble the intermediate stage between the oligodendrocyte precursor cell and the mature oligodendrocyte. A more immature phenotype, characterized by cells with a bipolar morphology, was induced by incubation with $10 \mathrm{ng} / \mathrm{mL}$ recombinant platelet-derived growth factor-AA (PeproTech, Rocky Hill, NJ) and 10 $\mathrm{ng} / \mathrm{mL}$ basic fibroblast growth factor (PeproTech) $(12,13)$ for $5 \mathrm{~d}$, whereas maturation, featuring multipolar cell character and intense arborization, was induced by $10 \mathrm{ng} / \mathrm{mL}$ ciliary neurotrophic factor (PeproTech), $5 \mu \mathrm{M}$ forskolin (Sigma Chemical Co.-Aldrich, Deisenhofen, Germany), and 15 nM 3,3',5-triiodo-L-thyronine (Sigma Chemical Co.-Aldrich) (14).

The human neuroblastoma cell line SH-SY5Y was obtained from the German Collection of Microorganisms and Cell Cultures (Braunschweig, Germany). The rat microglia cell line BV-2 was provided by Dr. E. Blasi (University of Modena and Reggio Emilia, Modena, Italy). All cells were kept at $37^{\circ} \mathrm{C}$ and $5 \% \mathrm{CO}_{2}$. Cell culture medium that consisted of Dulbecco's modified Eagle's medium (Biochrom, Berlin, Germany) with $4.5 \mathrm{~g} / \mathrm{L}$ D-glucose (OLN-93) or $3 \mathrm{~g} / \mathrm{L}$ D-glucose (BV-2/SH-SY5Y), respectively, was supplemented with $10 \%$ FCS and $1 \%$ human serum albumin.

Reagents. Stock solutions $(0.1 \mathrm{M})$ of GA, GC (Sigma Chemical Co.Aldrich), and 3-OH-GA (gift of Dr. E. Gerstner, Philipps-University, Marburg, Germany) were prepared in culture medium, adjusted to $\mathrm{pH} 7.4$ with $2 \mathrm{~N}$ $\mathrm{NaOH}$, filtered through $0.2-\mu \mathrm{M}$ microfilters, and diluted just before use. A $1-\mathrm{mM}$ stock solution of the protein kinase inhibitor staurosporine (Sigma Chemical Co.-Aldrich) was prepared in DMSO. The NMDA receptor antagonist dizocilpine (MK801) and the selective AMPA receptor antagonist 4-(8methyl-9H-1,3-dioxolo[4,5-h][2,3]benzodiazepin-5-yl)-benzenamine hydrochloride (GYKI 52466) were obtained from Tocris (Bristol, UK).

Assessment of glutamate receptor expression by reverse transcriptionPCR. Total RNA from OLN-93 cells was isolated by acidic phenol/chloroform extraction and treated with DNase I. Before reverse transcription, possible DNA contamination was examined by running RNA samples on a $2 \%$ agarose gel, subsequently developed with ethidium bromide. RNA (500 ng) was reverse-transcribed with M-MLV (Moloney murine leukemia virus) reverse transcriptase (Promega, Madison, WI) in $25 \mu \mathrm{L}$ of reaction mixture. The resulting cDNA $(1 \mu \mathrm{L})$ was amplified by PCR using primer pairs, as depicted in Table 1.

mRNA expressions of NMDA receptor subunit 1 (NR-1), 2A (hNR2A), 2B (GRIN2B), and 2D (GRIN2D) and AMPA receptor subunit GluR3 and GluR4 were studied by reverse transcription-PCR. cDNA amplification was performed in 32 cycles, consisting of denaturation $\left(45 \mathrm{~s}\right.$ at $\left.94^{\circ} \mathrm{C}\right)$, annealing $(1$ min at 50 or $\left.56^{\circ} \mathrm{C}\right)$, and primer extension $\left(1 \mathrm{~min}\right.$ at $\left.72^{\circ} \mathrm{C}\right)$. Amplified cDNA was subjected to $5 \%$ PAGE and subsequent silver staining.

Annexin-V measurement. A measurable feature of apoptosis is the loss of plasma membrane asymmetry. In normal cells, membrane phospholipids are distributed asymmetrically between the inner and outer leaflets of the plasma membrane. Phosphatidylserine, an aminophospholipid, is normally present in the inner leaflet of the plasma membrane. Early in apoptosis, before loss of membrane integrity, phosphatidylserine translocates from the inner to the outer leaflet, exposing it to the external cellular environment at the surface of the plasma membrane. Phosphatidylserine translocation can be assessed by $\mathrm{Ca}^{2+}$-dependent high-affinity binding to Annexin-V. Recombinant human Annexin-V-FITC (Bender Medsystems, Vienna, Austria) was used following the recommended protocol to detect early stage of ongoing apoptosis by flow cytometry (FL-1 channel). For discriminating apoptotic from necrotic events, propidium iodide (50 $\mu \mathrm{g} / \mathrm{mL}$; Sigma Chemical Co--Aldrich) was used as a second fluorescent marker, with cells undergoing necrosis with subsequent propidium iodide uptake showing a strong signal in the FL-2 channel. Flow cytometry was performed by a fluorescence-activated cell sorter (FACScan; Becton Dickinson, Heidelberg, Germany), and data were analyzed by Win MDI 2.8 software (Windows Multiple Document Interface for Flow Cytometry; http://facs.scripps.edu/software.html).

Caspase-3 detection. Caspase- 3 has been recognized as a central player in mediating the effector stage of apoptosis by initiating the process of DNA fragmentation. Activation of caspase-3 in living cells was assessed by the caspase-3 Activity Assay (Oncogene, San Diego, CA) following the manufacturer's instruction. The assay uses a FITC-labeled MAb directed against the cleaved (activated) form of caspase-3. The FITC label allows for direct detection of activated caspase- 3 in apoptotic cells by flow cytometry. Samples were analyzed by using the FL-1 channel of the flow cytometer.

Cell-cycle DNA staining with propidium iodide. Cells that have undergone DNA fragmentation lose DNA fragments after ethanol-mediated cell membrane permeabilization and are picked up by their reduced overall DNA content, as measured by flow cytometry (sub-G1 fraction) (15). Cells were resuspended in Hanks' balanced salt solution (Biochrom, Berlin, Germany), chilled $70 \%$ ethanol was added to a final concentration of $60 \%$, and the cells were stored at $-20^{\circ} \mathrm{C}$ for $1-2 \mathrm{~d}$. Cells were pelleted and resuspended in $0.5 \mathrm{~mL}$ of $70 \%$ ethanol and washed and finally resuspended in $1 \mathrm{~mL}$ of Hanks' balanced salt solution. Then, $0.5 \mathrm{~mL}$ of $0.2 \mathrm{M} \mathrm{Na}_{2} \mathrm{HPO}_{4}$ adjusted to $\mathrm{pH} 7.8$ with $0.1 \mathrm{M}$ citric acid was added for $5 \mathrm{~min}$. Cells were spun down, the supernatant was discarded, and $50 \mu \mathrm{L}$ of DNase-free RNAse was added (0.1 $\mathrm{mg} / \mathrm{mL}$; Sigma Chemical Co.-Aldrich). After $10 \mathrm{~min}$ at room temperature, 200 $\mu \mathrm{L}$ of PBS that contained $50 \mu \mathrm{g} / \mathrm{mL}$ propidium iodide was added and allowed to react for $10 \mathrm{~min}$ in the dark. Cells were analyzed by FACScan flow cytometer (Becton Dickinson), with 20,000 events per sample being collected. Data analysis was performed by WIN MDI 2.8 and Cylchred program (http://www.facslab.toxikologie.uni-mainz.de).

Colorimetric viability assay. The 3-(4,5-dimethylthiazol-2-yl)-2,5-diphenyl tetrazolium (MTT) assay was used to estimate cell viability as described (16).

Table 1. Primer pairs of NMDA and AMPA receptor subunits used to assess glutamate receptor expression by PCR

\begin{tabular}{|c|c|c|c|c|c|}
\hline Target & \multicolumn{2}{|c|}{ Primer location } & Sequence $\left(5^{\prime}-3^{\prime}\right)$ & Size (bp) & $\begin{array}{l}\text { GenBank } \\
\text { acc. no. }\end{array}$ \\
\hline \multirow[t]{2}{*}{ NR-1 } & Sense & $906-926$ & GAGAAGGAGAACATCACCGAC & 575 & L05666 \\
\hline & Antisense & $1460-1480$ & TCCTGTGTGCCGAACTTGCCA & & \\
\hline $\mathrm{hNR} 2 \mathrm{~A}$ & Antisense & $1250-1269$ & ATTCCCGGTCTTTGTTCAGC & & \\
\hline \multirow[t]{2}{*}{ GRIN2B } & Sense & $328-349$ & TCAAGGATGCCCACGAGAAG & 565 & U88963 \\
\hline & Antisense & $872-892$ & GTGGCTTCTTCCTTGGTACAG & & \\
\hline \multirow[t]{2}{*}{ GluR3 } & Sense & $71-89$ & ATGGGGCAAAGCGTGCTCC & 328 & M85036 \\
\hline & Antisense & 381-399 & AAGGAGGTCAGGGTGTTCAT & & \\
\hline \multirow[t]{2}{*}{ GluR4 } & Sense & $162-179$ & ATGAGGATTATTTGCAGG & 280 & M85037 \\
\hline & Antisense & $424-442$ & ATGGCAAACACCCCTCTAG & & \\
\hline
\end{tabular}


Metabolism of the yellow dye MTT by live mitochondria results in a color switch toward violet. MTT is cleaved by all living, metabolically active cells but not dead cells. The amount of formazan generated is directly proportional to the cell number over a wide range, if used in a homogeneous cell population. MTT (Sigma Chemical Co.-Aldrich) was dissolved in PBS at $5 \mathrm{mg} / \mathrm{mL}$ (stock solution) and sterilized by filtration. Cells were seeded in flat-bottom 96-well microtiter plates $\left(50,000-100,000\right.$ cells/well) and grown for $24 \mathrm{~h}$ at $37^{\circ} \mathrm{C}$. Then, various concentrations of GA, GC, or 3-OH-GA were added for another $24 \mathrm{~h}$. Finally, $10 \mu \mathrm{L}$ of MTT $(5 \mathrm{mg} / \mathrm{mL}$ ) was added to the wells (final concentration $0.5 \mathrm{mg} / \mathrm{mL}$ ) for $3 \mathrm{~h}$, and the reaction was stopped by addition of $100 \mu \mathrm{L}$ of isopropanol that contained $0.04 \mathrm{~N} \mathrm{HCl}$. Absorbance was read in a microplate reader (BioRad, Munich, Germany) at $570 \mathrm{~nm}$ and a reference wavelength of $650 \mathrm{~nm}$. Data were compared by $t$ test, with $p<0.05$ indicating significance.

\section{RESULTS}

GA and its metabolites $\mathrm{GC}$ and 3-OH-GA dose-dependently reduce OLN-93 cell viability. When OLN-93 were exposed to $10 \mathrm{mM} \mathrm{GA}, \mathrm{GC}$, or 3-OH-GA for $24 \mathrm{~h}$, cell viability decreased sharply (Fig. 1). When assessed by MTT metabolism, the toxicity of all three organic acids was found to be dose dependent, with changes being readily observed at concentrations as low as $0.1 \mathrm{mM}$ (Fig. 2). In contrast, no effects of GA, $\mathrm{GC}$, and 3-OH-GA were seen with the neuroblastoma cell line (SH-SY5Y) or the microglia cell line (BV-2; data not shown).

$G A, G C$, and 3-OH-GA induce early and late steps of apoptosis. Apoptosis involves a series of sequential events that can be measured in vitro. Early during apoptosis, phosphatidylserine (PS) is externalized and thus becomes accessible for Annexin-V. GA-, GC-, or 3-OH-GA-exposed OLN-93 cells
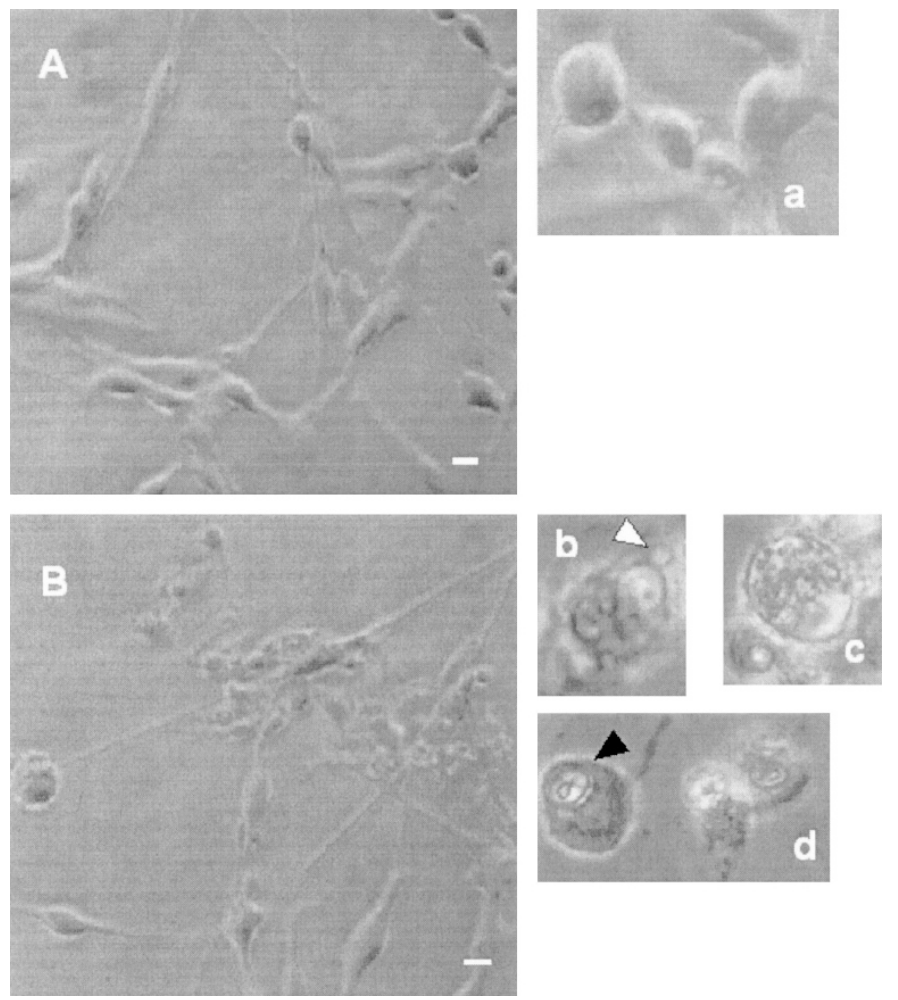

Figure 1. Representative transmission light phase contrast photomicrographs of OLN-93 cell cultures after $24 \mathrm{~h}$ of incubation with $10 \mathrm{mM}$ GA. Photomicrographs were taken by Olympus digital camera. Controls $(A$ and $a$ ) are intact cells without signs of apoptosis; GA-treated cells $(B)$ show plasma membrane blebbing ( $b$, white arrowhead), chromatin fragmentation $(c)$, and chromatin condensation $(d$, black arrowhead). White bars $=10 \mu \mathrm{m}$.

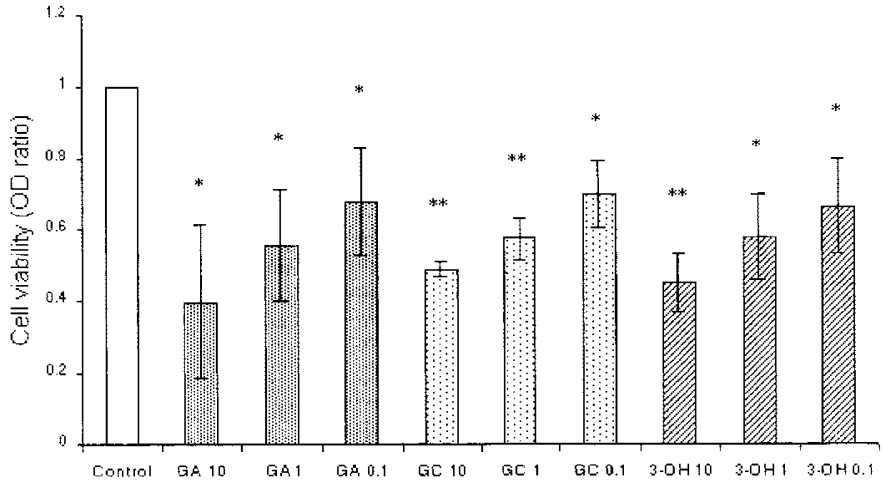

Figure 2. OLN-93 cell viability, as measured by metabolization of MTT (OD ratio), after $24 \mathrm{~h}$ of incubation with GA, GC, or 3-OH-GA at concentrations of $0.1,1$, or $10 \mathrm{mM}$ (mean and SD of three independent experiments). ${ }^{*} p<0.05$; $* * p<0.01$.

were found to bind more FITC-labeled Annexin- $\mathrm{V}$ than controls (Fig. 3). Activation of the effector caspase-3 was assessed by intracellular binding of a FITC-labeled MAb specific to the activated (cleaved) form of the enzyme. The percentage of cells that displayed activated caspase- 3 was found to increase alongside the concentrations of GA, GC, or 3-OH-GA used (Fig. 4). When the total DNA content of cells was assessed by propidium iodide staining of permeabilized cells, the number of cells with subnormal DNA content secondary to the loss of apoptosis-generated small DNA fragments was significantly increased (Fig. 5).

Toxicity of GA, GC, and 3-OH-GA on OLN-93 cells is abrogated by the pan-caspase inhibitor z-VAD-fmk. For assessing whether inhibition of caspases could block the programmed cell death induced by GA, GC, and 3-OH-GA, the
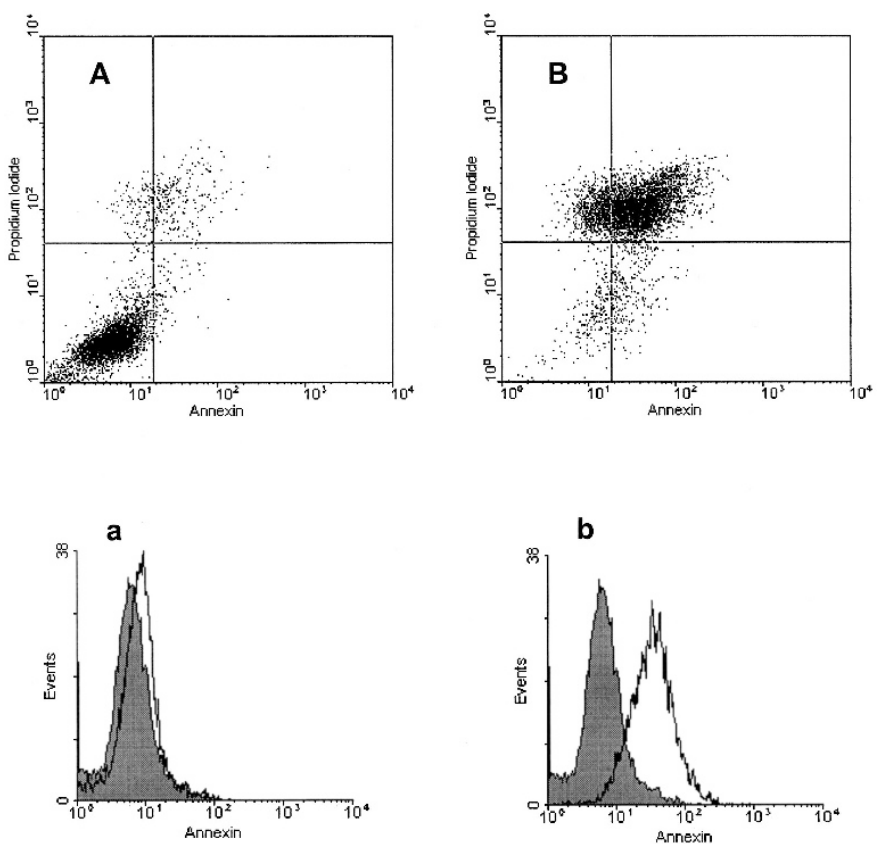

Figure 3. Flow cytometry analysis of annexin-V surface binding ( $x$ axis) and propidium iodide uptake ( $y$ axis) of OLN-93 exposed to $10 \mathrm{mM} \mathrm{GA}$ for $24 \mathrm{~h}$. ( $A$ and $a$ ) Controls. ( $B$ and $b$ ) GA-treated cells. ( $A$ and $B$ ) Dot plots. ( $a$ and $b$ ) Histograms, showing FITC-annexin-V binding (open curve) $v s$ background control fluorescence (shaded). $x$ axis, fluorescence intensity; $y$ axis, number of cells. 


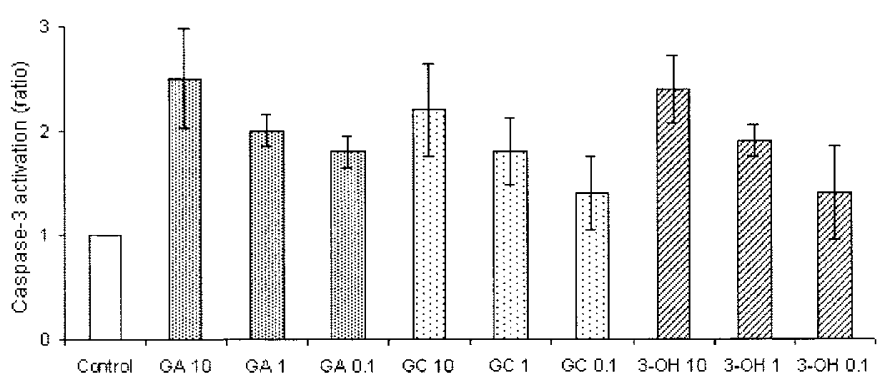

Figure 4. Activation of the effector caspase-3, as assessed by intracellular binding of a FITC-labeled MAb specific for the activated (cleaved) form of the enzyme, using flow cytometry. OLN-93 cells were incubated with GA, GC, or 3-OH-GA at concentrations of $0.1,1$, or $10 \mathrm{mM}$ for $24 \mathrm{~h}$ before analysis (mean and SD of three independent experiments). $* p<0.05 ; * * p<0.01$.
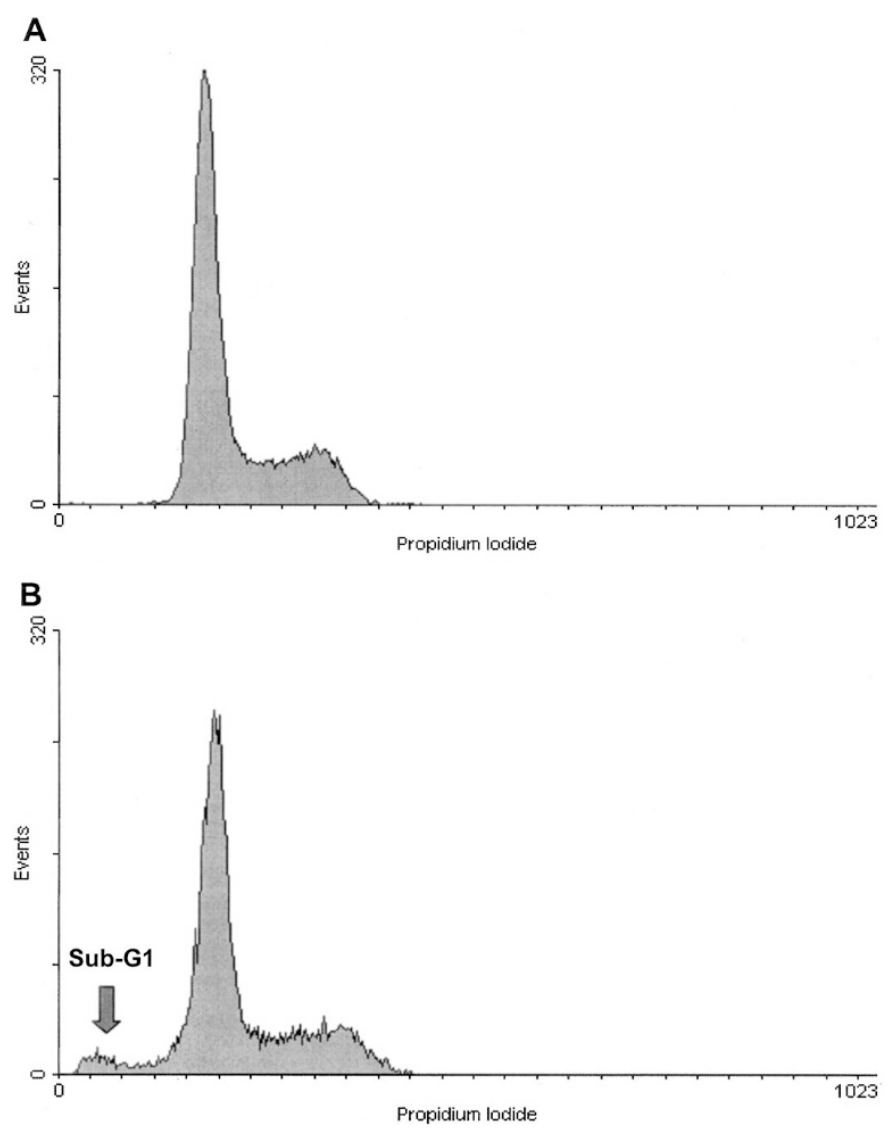

Figure 5. DNA content of control $(A)$ and $10 \mathrm{mM}$ GC-treated OLN-93 cells $(B)$, assessed after permeabilization and subsequent propidium iodide staining, using flow cytometry. The main peak represents cells in G0/G1 phase of the cell cycle. The proportion of cells with subnormal DNA content (sub-G1), secondary to loss of cleaved DNA fragments generated by the apoptotic

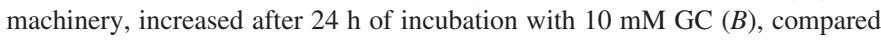
with controls $(A)$.

pan-caspase inhibitor z-VAD-fmk ( $40 \mu \mathrm{M}$ final concentration; Promega) was added together with the organic acids tested. This treatment completely abrogated the effects of GA, GC, or 3-OH-GA (Fig. 6).

Excitotoxicity is not a major mechanism of GA-, GC-, and 3-OH-GA-mediated toxicity in OLN-93 cells. Reverse transcription-PCR analysis of OLN-93 cells failed to detect transcripts of the genes coding for the NDMA receptor subunits NR1, NR2A, and NR2B, whereas cells that expressed the
$24 \mathrm{~h}$ incubation with $\mathrm{GA}, \mathrm{GC}$, or 3-OH-GA

$24 \mathrm{~h}$ incubation with $\mathrm{GA}, \mathrm{GC}$, or 3-OH-GA plus $z-\mathrm{VAD}$-fmk

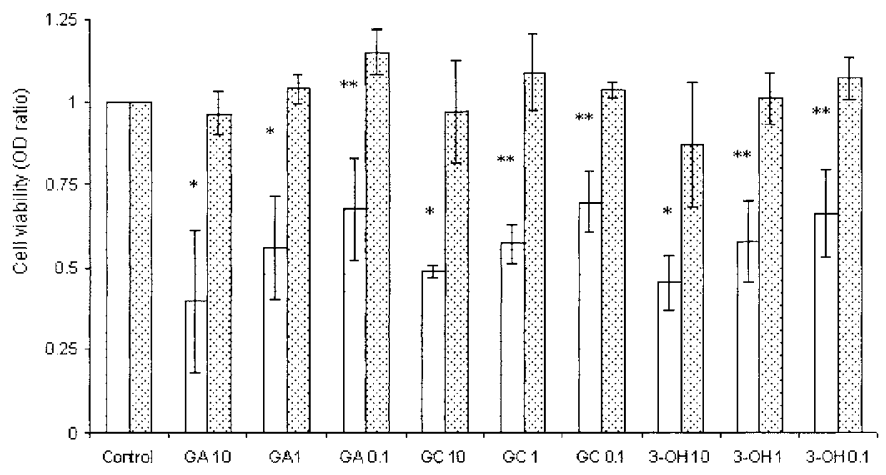

Figure 6. Involvement of caspases in toxicity mediated by GA, GC, or 3-OH-GA $(0.1,1$, or $10 \mathrm{mM}, 24 \mathrm{~h})$ was assessed using the pan-caspase inhibitor Z-VAD-fmk. OLN-93 cell viability was determined via metabolization of MTT (OD ratio, mean and SD). z-VAD-fmk (40 $\mu \mathrm{M}$ final concentration) was added together with the organic acids tested. *p $<0.05 ; * * p<0.01$. $\square 24$ h incubation with GA, GC, or 3-OH-GA, $\square 24$ h incubation with GA, GC, or 3-OH-GA plus Z-VAD-fmk.

NR2D and AMPA receptor subunits GluR3, GluR4, NR1, NR2A, or NR2B transcripts were readily detected in total CNS control RNA. Neither the NMDA receptor antagonist MK801 nor the AMPA receptor antagonist GYKI was able to prevent the reduction of cell viability observed with GA, GC, and 3-OH-GA (data not shown).

Both oligodendrocyte precursor cells and more mature oligodendrocytes are susceptible to $\mathrm{GA}$-, GC-, and 3-OH-GAmediated toxicity. After OLN-93 were cultured in the presence of platelet-derived growth factor-AA and basic fibroblast growth factor for 5-7 d, an O-2A progenitor-type bipolar morphology emerged, consistent with partial dedifferentiation (14). Conversely, when cultured in the combined presence of ciliary neurotrophic factor, forskolin, and triiodo-thyronine, cells displayed the intensive arborization characteristic of more mature oligodendrocytes. When exposed to GA, 3-OH-GA, or GC, both precursor cells and mature oligodendrocytes showed increased annexin- $\mathrm{V}$ binding, which was slightly more pronounced in the precursor cell type (data not shown).

\section{DISCUSSION}

These data show that the organic acids GA, GC, and 3-OH-GA specifically induce apoptosis in the immature oligodendroglia cell line OLN-93. GA-, GC-, or 3-OH-GAmediated oligodendrocyte cell death bears the hallmarks of various steps of apoptosis and can be blocked by the pancaspase inhibitor z-VAD-fmk.

Until recently, most investigations have focused on the toxicity of GA and 3-OH-GA for neurons, which is thought to involve NMDA receptor-mediated excitotoxicity. As GA poorly penetrates the blood-brain barrier, GDD has been difficult to study in animal models. Targeted deletion of the gene encoding glutaryl-CoA dehydrogenase in murine embryonic stem cells has allowed for the generation of mice with a 
biochemical phenotype closely resembling human GDD (10). Surprising, these mice show no evidence of neuronal loss but display mild motor deficits. Pathologically, they are characterized by diffuse spongiform white matter disease. White matter abnormalities, including dys- and demyelination, have also been observed in human GDD. In adult-onset GDD, they seem to be the prominent feature on MRI (9). We believe that the hitherto unexplained leukoencephalopathy is related to direct oligodendroglia cell destruction caused by GA and its metabolites.

For neurons, the main mechanism that causes cell damage after GA exposure seems to be necrosis (17). In contrast, the main damage mechanism in oligodendrocytes seems to be apoptosis. GA, GC, and 3-OH-GA dose-dependently induced phosphatidyl-serine externalization, caspase- 3 activation, and DNA fragmentation. Moreover, the loss of cell viability caused by $\mathrm{GA}, \mathrm{GC}$, and 3-OH-GA could be prevented by the pancaspase inhibitor z-VAD-fmk, clearly establishing classical (caspase-dependent) apoptosis as the main mechanism responsible for GA-, GC-, and 3-OH-GA-mediated oligodendrocyte cell death.

GA- and 3-OH-GA-triggered neuronal damage has been reported to be mediated by excitotoxicity involving the NDMA receptor (18), although no specific binding to NMDA receptors could be demonstrated (3). Specifically, GA and 3-OH-GA toxicity was found to depend on expression of the NR1 and NR2B subunits of the NMDA receptor. In contrast, OLN-93 oligodendrocytes did not express these NMDA receptor subunits that are essential for NMDA-mediated excitotoxicity (4). Moreover, GA-, 3-OH-GA-, and GC-mediated oligodendrocyte apoptosis could not be prevented by preincubation with the nonselective NMDA receptor antagonist MK801 or the AMPA receptor antagonist GYKI. In various studies, oligodendrocytes have been found to express functional AMPA receptor but little or no NMDA receptor. Overstimulation of AMPA receptors has been shown to induce excitotoxic damage in oligodendroglia in vitro and in vivo $(19,20)$. However, excitotoxicity does not contribute significantly to apoptosis induced in oligodendrocytes that are exposed to GA, 3-OHGA, or GC. Bjugstad et al. (21) also found that GA/3-OHGA-mediated cell death is not necessarily mediated by glutamate receptors: neurotoxicity in striatal and cortical cultures of embryonic rat striatum could not been prevented by glutamate antagonists MK801 and NBQX.

Both GA and GC have been shown to directly induce mitochondrial permeability transition (22). Whereas opening the permeability transition pore features prominently among apoptotic pathways (23), induction of apoptosis by various triggers, including branched chain amino acids, may proceed in the absence of mitochondrial permeability transition (24). The role of mitochondria in mediating GA-, 3-OH-GA-, and GCtriggered oligodendrocyte apoptosis remains to be determined.

Oligodendrocytes develop from oligodendrocyte precursor cells in forebrain and cerebellum (25) during late gestational and early postnatal development. Oligodendroglial progenitor cells exist in the subventricular zone and migrate into the intermediate zone and cortical plate, where they differentiate into immature oligodendrocytes, which mature and myelinate axons (26). Postnatal cerebral ultrasounds of patients with GA-1 often show bilateral subependymal cysts (27). Oligodendrocyte development depends also on interactions with other cells in the CNS, in particular, with neurons that synthesize and release factors that are essential for oligodendrocyte precursor cells, including glutamate (28). Glutamate-mediated activation of AMPA receptors generates large depolarizing currents, inducing immediate expression of genes. Immature oligodendrocytes are more vulnerable and more susceptible to AMPA receptor-mediated damage than mature oligodendrocytes $(14,19)$. Both immature and mature oligodendrocytes seemed to be susceptible to GA-, GC-, or 3-OH-GA-mediated induction of apoptosis, which seemed more pronounced in the precursor cell type. In contrast to OLN-93 cells, SH-SY5Y neuroblastoma or BV-2 microglia cells were resistant to GA, 3-OH-GA, or GC up to concentrations of $10 \mathrm{mM}$. Whereas neurotoxicity of GA and 3-OH-GA seems to be maturation dependent (17), susceptibility to apoptosis mediated by GA, 3-OH-GA, or GC seems to be more a matter of lineage than maturity. However, the SH-SY5Y and BV-2 cell lines may be poor models for studying neuronal and microglial cells in vitro, and experiments involving freshly prepared cells are preferred $(2,17,21,29)$.

In addition to excitotoxicity, GA and its metabolites exert various effects, including inhibition of mitochondrial respiratory chain activity, energy production (30), generation of reactive oxygen species $(4,6)$, depletion of intracellular creatine phosphate stores (3), and inhibition of the $\mathrm{Na}^{+} / \mathrm{K}^{+}$-ATPase of the plasma membrane (29). These biochemical disturbances require GA concentrations encountered during metabolic imbalances and may be important for the development of neuronal necrosis associated with metabolic decompensation. Little is known about cerebrospinal fluid and brain tissue concentrations of GA and its metabolites in GDD patients (1), and there is a complete lack of fetal data. Whereas in most experimental settings described in this article, oligodendrocyte apoptosis was observed with concentrations as little as $0.1 \mathrm{mM}$, neuronal apoptosis was elicited experimentally using higher concentrations, up to $50 \mathrm{mM}(2-4,17,21,30)$. Moreover, although experiments have been performed with GA, 3-OH-GA, or GC, all three substances are present within in vivo situations. Morphologic changes of the brain in patients with GDD already develop in utero and are readily visualized by ultrasound in the fetus and the asymptomatic newborn $(31,32)$. Therefore, we propose a dual action of GA and its metabolites in patients with GDD: moderately increased concentrations, as encountered in utero and in patients who are subjected to rigorous dietary treatment, induce oligodendrocyte apoptosis, whereas peak concentrations during metabolic compensation precipitate neuronal necrosis.

Acknowledgments. We thank Evelyn Strauss for excellent technical assistance and Dr. D. Stibenz for helpful discussion.

\section{REFERENCES}

1. Hoffmann GF, Athanassopoulos S, Burlina AB, Duran M, de Klerk JB, Lehnert W, Leonard JV, Monavari AA, Müller E, Muntau AC, Naughten ER, Plecko-Starting B, Superti-Furga A, Zschocke J, Christensen E 1996 Clinical course, early diagnosis, 
treatment, and prevention of disease in glutaryl-CoA dehydrogenase deficiency. Neuropediatrics 27:115-123

2. Kölker S, Ahlemeyer B, Krieglstein J, Hoffmann GF 1999 3-Hydroxyglutaric and glutaric acids are neurotoxic through NMDA receptors in vitro. J Inherit Metab Dis 22:259-262

3. Ullrich K, Flott-Rahmel B, Schluff P, Musshoff U, Das A, Lucke T, Steinfeld R, Christensen E, Jakobs C, Ludolph A, Neu A, Roper R 1999 Glutaric aciduria type I: pathomechanisms of neurodegeneration. J Inherit Metab Dis 22:392-403

4. Kölker S, Ahlemeyer B, Krieglstein J, Hoffmann GF 2001 Contribution of reactive oxygen species to 3-hydroxyglutarate neurotoxicity in primary neuronal cultures from chick embryo telencephalons. Pediatr Res 50:76-82

5. Latini A, Borba Rosa R, Scussiato K, Llesuy S, Bello-Klein A, Wajner M 2002 3-Hydroxyglutaric acid induces oxidative stress and decreases the antioxidant defenses in cerebral cortex of young rats. Brain Res 956:367-373

6. de Oliveira Marques F, Hagen ME, Pederzolli CD, Sgaravatti AM, Durigon K, Testa CG, Wannmacher CM, de Souza Wyse AT, Wajner M, Dutra-Filho CS 2003 Glutaric acid induces oxidative stress in brain of young rats. Brain Res 964:153-158

7. Brismar J, Ozand PT 1995 CT and MR of the brain in glutaric acidemia type I: a review of 59 published cases and a report of 5 new patients. AJNR Am J Neuroradiol 16:675-683

8. Soffer D, Amir N, Elpeleg ON, Gomori JM, Shalev RS, Gottschalk-Sabag S 1992 Striatal degeneration and spongy myelinopathy in glutaric acidemia. J Neurol Sci 107:199-204

9. Bahr O, Mader I, Zschocke J, Dichgans J, Schulz JB 2002 Adult onset glutaric aciduria type I presenting with a leukoencephalopathy. Neurology 59:1802-1804

10. Koeller DM, Woontner M, Crnic LS, Kleinschmidt-DeMasters B, Stephens J, Hun EL, Goodman SI 2002 Biochemical, pathologic and behavioral analysis of a mouse model of glutaric acidemia type I. Hum Mol Genet 11:347-357

11. Richter-Landsberg C, Heinrich M 1996 OLN-93: a new permanent oligodendroglia cell line derived from primary rat brain glial cultures. J Neurosci Res 45:161-173

12. McKinnon RD, Matsui T, Dubois-Dalcq M, Aaronson SA 1990 FGF modulates the PDGF-driven pathway of oligodendrocyte development. Neuron 5:603-614

13. Raff MC, Lillien LE, Richardson WD, Burne JF, Noble MD 1988 Platelet-derived growth factor from astrocytes drives the clock that times oligodendrocyte development in culture. Nature 333:562-565

14. Back SA, Gan X, Li Y, Rosenberg PA, Volpe JJ 1998 Maturation-dependent vulnerability of oligodendrocytes to oxidative stress-induced death caused by glutathione depletion. J Neurosci 18:6241-6253

15. Kettritz R, Xu YX, Faass B, Klein JB, Müller EC, Otto A, Busjahn A, Luft FC, Halle H 2000 TNF- $\alpha$-mediated neutrophil apoptosis involves Ly-GDI, a Rho GTPase regulator. J Leukoc Biol 68:277-283

16. Bührer C, Atzpodien J, Öz S, Henze G 1991 Fosfomycin does not reduce cytostatic activity of cis-platinum against human osteosarcoma cell lines in vitro. Pediatr Hematol Oncol 8:243-249

17. Kölker S, Ahlemeyer B, Krieglstein J, Hoffmann GF 2000 Maturation-dependen neurotoxicity of 3-hydroxyglutaric and glutaric acids in vitro: a new pathophysiologic approach to glutaryl-CoA dehydrogenase deficiency. Pediatr Res 47:495-503
18. Kölker S, Ahlemeyer B, Krieglstein J, Hoffmann GF 2000 Cerebral organic acid disorders induce neuronal damage via excitotoxic organic acids in vitro. Amino Acids $18: 31-40$

19. Kavanaugh B, Beesley J, Itoh T, Itoh A, Grinspan J, Pleasure D 2000 Neurotrophin-3 (NT-3) diminishes susceptibility of the oligodendroglial lineage to AMPA glutamate receptor-mediated excitotoxicity. J Neurosci Res 60:725-732

20. McDonald JW, Althomsons SP, Hyrc KL, Choi DW, Goldberg MP 1998 Oligodendrocytes from forebrain are highly vulnerable to AMPA/kainate receptor-mediated excitotoxicity. Nat Med 4:291-297

21. Bjugstad KB, Zawada WM, Goodman S, Free CR 2001 IGF-1 and bFGF reduce glutaric acid and 3-hydroxyglutaric acid toxicity in striatal cultures. J Inherit Metab Dis 24:631-647

22. Palmeira CM, Rana MI, Frederick CB, Wallace KB 2000 Induction of the mitochondrial permeability transition in vitro by short-chain carboxylic acids. Biochem Biophys Res Commun 272:431-435

23. Newmeyer DD, Ferguson-Miller S 2003 Mitochondria: releasing power for life and unleashing the machineries of death. Cell 112:481-490

24. Jouvet P, Rustin P, Taylor DL, Pocock JM, Felderhoff-Müeser U, Mazarakis ND, Sarraf C, Joashi U, Kozma M, Greenwood K, Edwards AD, Mehmet H 2000 Branched chain amino acids induce apoptosis in neural cells without mitochondrial membrane depolarization or cytochrome c release: implications for neurological impairment associated with maple syrup urine disease. Mol Biol Cell 11:1919-1932

25. Kagawa T, Wada T, Ikenaka K 2001 Regulation of oligodendrocyte development. Microsc Res Tech 52:740-745

26. Levison SW, Goldman JE 1993 Both oligodendrocytes and astrocytes develop from progenitors in the subventricular zone of postnatal rat forebrain. Neuron 10:201-212

27. Monavari AA, Naughten ER 2000 Prevention of cerebral palsy in glutaric aciduria type 1 by dietary management. Arch Dis Child 82:67-70

28. Hardy R, Reynolds R 1993 Neuron-oligodendroglial interactions during centra nervous system development. J Neurosci Res 36:121-126

29. Kölker S, Okun JG, Ahlemeyer B, Wyse AT, Hörster F, Wajner M, Kohlmüller D, Mayatepek E, Krieglstein J, Hoffmann GF 2002 Chronic treatment with glutaric acid induces partial tolerance to excitotoxicity in neuronal cultures from chick embryo telencephalons. J Neurosci Res 68:424-431

30. Silva CG, Silva AR, Ruschel C, Helegda C, Wyse AT, Wannmacher CM, Dutra-Filho CS, Wajner M 2000 Inhibition of energy production in vitro by glutaric acid in cerebral cortex of young rats. Metab Brain Dis 15:123-131

31. Forstner R, Hoffmann GF, Gassner I, Heideman P, De Klerk JB, Lawrenz-Wolf B, Döringer E, Weiss-Wichert P, Tröger J, Colombo JP, Plöchl E 1999 Glutaric aciduria type I: ultrasonographic demonstration of early signs. Pediatr Radiol 29:138-143

32. Lin SK, Hsu SG, Ho ES, Tsai CR, Hseih YT, Lo FC, Lai HY, Chen MH 2002 Glutaric aciduria (type I): prenatal ultrasonographic findings. Ultrasound Obstet Gynecol 20:305-307 